Article

\title{
Variability in the Control of Type 2 Diabetes in Primary Care and Its Association with Hospital Admissions for Vascular Events. The APNA Study.
}

\author{
Sara Guillen-Aguinaga 12, Luis Forga ${ }^{34}$, Antonio Brugos-Larumbe 2 , Francisco Guillen-Grima ${ }^{2456 *}$, Laura Guillén- \\ Aguinaga ${ }^{5}$ and Inés Aguinaga-Ontoso ${ }^{6}$ \\ 1 Navarra Health Service. Pamplona, Navarra. Spain. sguillen.4@alumni.unav.es \\ 2 Dept. Health Sciences. Public University of Navarra (UPNA). Pamplona, Spain. ablm649@gmail.com ; frguil- \\ len@unav.es; ines.aguinaga@unavarra.es \\ 3 Department of Endocrinology, Hospital of Navarra, C/ Irunlarrea s/n, Pamplona 31008, Spain \\ 4 Instituto de Investigación Sanitaria de Navarra (IdiSNA), C/ Irunlarrea s/n, Pamplona 31008, Spain.; \\ lluis.forga.llenas@navarra.es \\ 5 Clínica Universidad de Navarra. Pamplona, Navarra. Spain. lguillen@unav.es \\ 6 CIBER-OBN, Instituto de Salud Carlos III, Madrid, Spain. \\ * Correspondence: frguillen@unav.es; Tel.: (+34-948-296384)
}

\begin{abstract}
Type 2 diabetes (T2D) is associated with increased cardiovascular morbidity, mortality, and hospital admissions. There is variability in clinical practice. The objectives are to analyze the variability in the control of Blood Pressure (BP), HbA1c, and LDL-C in T2D patients and its influence on admissions due to cardiovascular events (CVE) Methods: We analyzed the electronic records in Primary Care Health centers in Navarra (Spain) and hospital admission for CVE. We follow 480637 people from 2012 to 2016. We calculated indicators of control of patients with T2D for each year, percentage with: HbA1c $<7 \%$; HbA1c $>=9 \%$; BP $<140 / 90 \mathrm{mmHg}$; LDL-C $<100 \mathrm{mg} / \mathrm{dl}$. We used logistic and Cox regression. Results: Patients in the best control GP practices cluster are 2.5 times more likely to have $\mathrm{HbA1c}<7 \%$ [OR: 2.46 (95\% CI: 2.29-3.64)]. Poor HbA1c control $\geq 9 \%$ is more likely in the worst control cluster [OR: 1.73 (95\% CI:1.63-1.83)]. The probability of admission for CVE increases with age, being male, low income, obesity, history of $\mathrm{CVE}$, having $\mathrm{HbA1c} \geq 9 \%$, and belonging to a GP practice in the cluster of $\mathrm{HbA} 1 \mathrm{C} \geq 9 \%$ worst control. In contrast, it decreases in patients with $\mathrm{HbA} 1 \mathrm{c}<7 \%, \mathrm{BP}<140 / 90 \mathrm{mmHg}$ and $\mathrm{LDL}<100 \mathrm{mg} / \mathrm{dl}$.
\end{abstract}

Keywords: Healthcare Disparities; Diabetes Mellitus, Type 2; Vascular Diseases; Primary Health Care; Cohort

\section{Introduction}

Type 2 diabetes (T2D) is a highly prevalent disease associated with increased cardiovascular morbidity and mortality and subsequent hospital admissions [1-3]. Cardiovascular risk factors in patients with T2D are mostly common to the general population. It could be divided into those that are modifiable (glycemic control, smoking, obesity, and hypertension and dyslipidemia)[4,5] and non-modifiable (family history of cardiovascular disease, years of T2D evolution, race, gender, age, age at T2D debut, and history of cardiovascular event) [6]. An association has also been found between low socioeconomic status and higher mortality in diabetic patients [7-13].

Glycosylated hemoglobin ( $\mathrm{HbA1c})$ is a widely used marker in detecting and monitoring diabetes. It is linearly related to the risk of vascular complications in both patients with diabetes and nondiabetic patients [14]. There is also evidence that elevated $\mathrm{HbA1c}$ predicts cardiovascular (CV) events [15]. Despite pharmacological advances and new devices 
for treating and controlling T2D, the clinical practice still has variability. Optimal control levels of $\mathrm{HbA1c}<7 \%$ are achieved in approximately only half of the population [16-18]. Two other valuable parameters in evaluating T2D follow-up are BP control and LDL-C due to their association with CVE [19]. Various guidelines recommend maintaining BP $<140 / 90 \mathrm{mg} / \mathrm{dl}$ and LDL-C levels $<100 \mathrm{mg} / \mathrm{dl}[2,4]$.

In Spain, primary health care centers (PHCC) carry out the care of T2D patients. In complex patients, PHCCs work in coordination with their referral hospital or outpatient Endocrinology services. Interventions in health centers aim to treat and control the disease and act on modifiable factors, following the recommendations of the different scientific societies $[2,4,20]$. Compliance with these recommendations is not as adequate as it could be, and there is significant variability depending on the different countries, regions, and even on the characteristics of the physician who monitors these patients [21-23]. How patients are cared for influences risk factors control, and treatment adherence $[23,24]$. The evolution of quality indicators in patients with T2D has been evaluated [25], including complications such as foot ulcers, amputations, and retinopathy [26]. However, little has been studied on their influence on the development of CVE. Is for that, it is interesting to know the level of compliance achievable in clinical practice. Achieving full compliance with the indicators does not depend solely on measures proposed by doctors. There are variables that they cannot control and that sometimes rely on their patients' adherence to treatment or others.

In Navarra, a computerized medical record is employed in primary care. It was implemented in 2000, and it was in general use since 2008. Our study is part of a series of studies included under the acronym "APNA Study" (Navarra Primary Care Study) that analyze data from the computerized medical record registry of Navarra, with different purposes. Many studies are done with the data from this registry that endorse the data quality in terms of T2D [27-30].

The objectives of our present study are to analyze the variability in the control of $\mathrm{HbA} 1 \mathrm{c}$, $\mathrm{BP}$, and LDL-C in type 2 diabetic patients with T2D and its influence on admissions for cardiovascular events.

\section{Materials and Methods}

We analyzed the care of patients with T2D from 2012 to 2016 in Navarra, a region located in northern Spain, where access to health care is universal. In Primary Care, Health centers work with family physicians. In all primary care health centers, a population group called "GP practice" or "quota" is assigned to a team formed by a family physician and a nurse responsible for their care. We studied 385 GP practices with a mean population of 1420 people (SD 342) with a range between 508 and 2165 at the end of cohort follow-up.

We analyzed the electronic records that show the clinical variables that doctors or nurses record in coded form during patients visits. We also collected the analytical results that are included electronically in the clinical history from the laboratories. We extracted from the hospital discharge registration system the date of the first hospital admission with a CVE as the main reason for admission during the follow-up period recorded as ischemic heart disease (ICD codes: 410-414; ICD10: I20-I25) or cerebrovascular disease (ICD: 430438; ICD10: I60-I69). Patients were followed up until an event occurred or until 31 December 2016.

\subsection{Study variables:}

We collected each year of the cohort, age, sex, health center, GP practice, date of T2D diagnoses made by physicians. The low-income status $<18,000$ euros/year, used in Spain to 
establish the pharmaceutical co-payment, is also identified. Clinical variables: the following variables were used: weight (kilograms), height (meters), Body Mass Index (BMI) (weight/height2), systolic and diastolic BP (mmHg), HbA1c \%, LDL-C (mg/dl), and smoker during the follow-up period. Based on BMI, obese patients were identified as those with a BMI $>30$. The values of the clinical variables before admission were collected. In the case of non-admission, the first value of the year was collected. The history of CVE is also recorded. The data were anonymized. The Clinical Research Ethics Committee of Navarra (CEIC) approved the study with the number 3/2014 on 26 March 2014.

\subsection{Statistical methods:}

We calculated four indicators of control of patients with T2D for each year: percentage with $\mathrm{HbA} 1 \mathrm{c}<7 \%$; percentage with $\mathrm{HbA} 1 \mathrm{c}>=9 \%$; percentage with $\mathrm{BP}<140 / 90 \mathrm{mmHg}$; percentage LDL-C $<100 \mathrm{mg} / \mathrm{dl}$. We analyzed the mean values of each indicator during the years of follow-up. To compare the prevalence between GP practices, we directly standardized rates by age, taking the population of Navarra as a reference. We show the $\%$ compliance and the coefficient of variation $(\mathrm{CV})$ to identify the variability between GP practices in compliance with the control indicators. We present the \% compliance and the coefficient of variation (CV). In addition, using a non-hierarchical K-means cluster analysis, we classified GP practices into two clusters according to the level of compliance. We consider clusters representing less than 3\% of the GP practices as outliers and excludes those GP practices from the analysis.

Using the Directed Acyclic Graphic (DAG) [31] (Figure 1), we studied the relationship of exposure cluster of $\mathrm{HbA} 1 \mathrm{c} \geq 9 \%$ with $\mathrm{CVE}$ and potential confounding factors: sex, age, low income, obesity, smoking, and CVE antecedent.

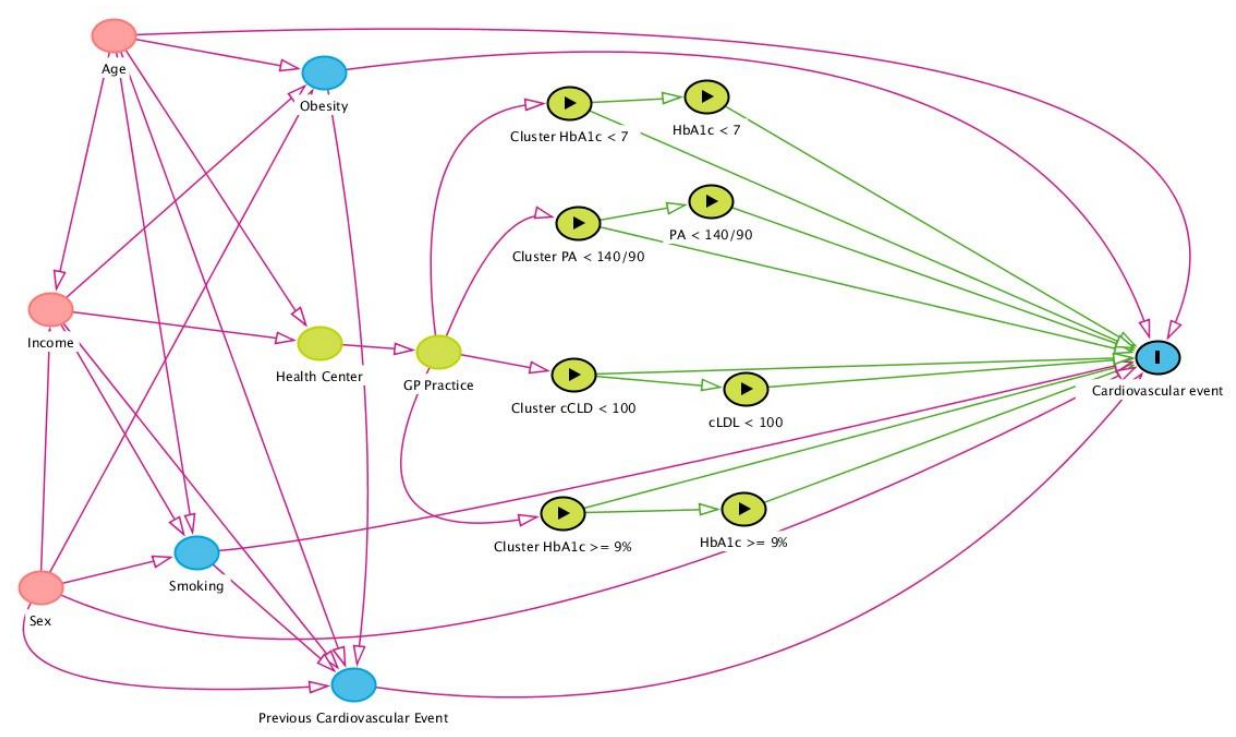

Figure 1. Directed Acyclic Graph (DAG) of the effect of Cluster of $\mathrm{HbAc}>=9 \%$ (exposure) on Cardiovascular event (outcome). Ancestors of exposure and outcome (red) ancestors of Outcome (Blue), ancestors of exposure (green), exposure (green \& $\downarrow$ ) Outcome (Blue \& $\mid$ ) Based on DAGitty version 3.0.

The DAG shows that age and income determine where people live and influence the health center they are linked to and the GP practice they belong to. Age and sex were related to the appearance of CVE and influenced antecedents of CVE, obesity, and current smoking. We observed that the cluster directly affects CVE and the control measure that 
affects the outcomes. The software indicated that to study the effects of cluster and controls in the outcome was necessary to adjust by sex, age, income, obesity, and current smoking (Figure 2).

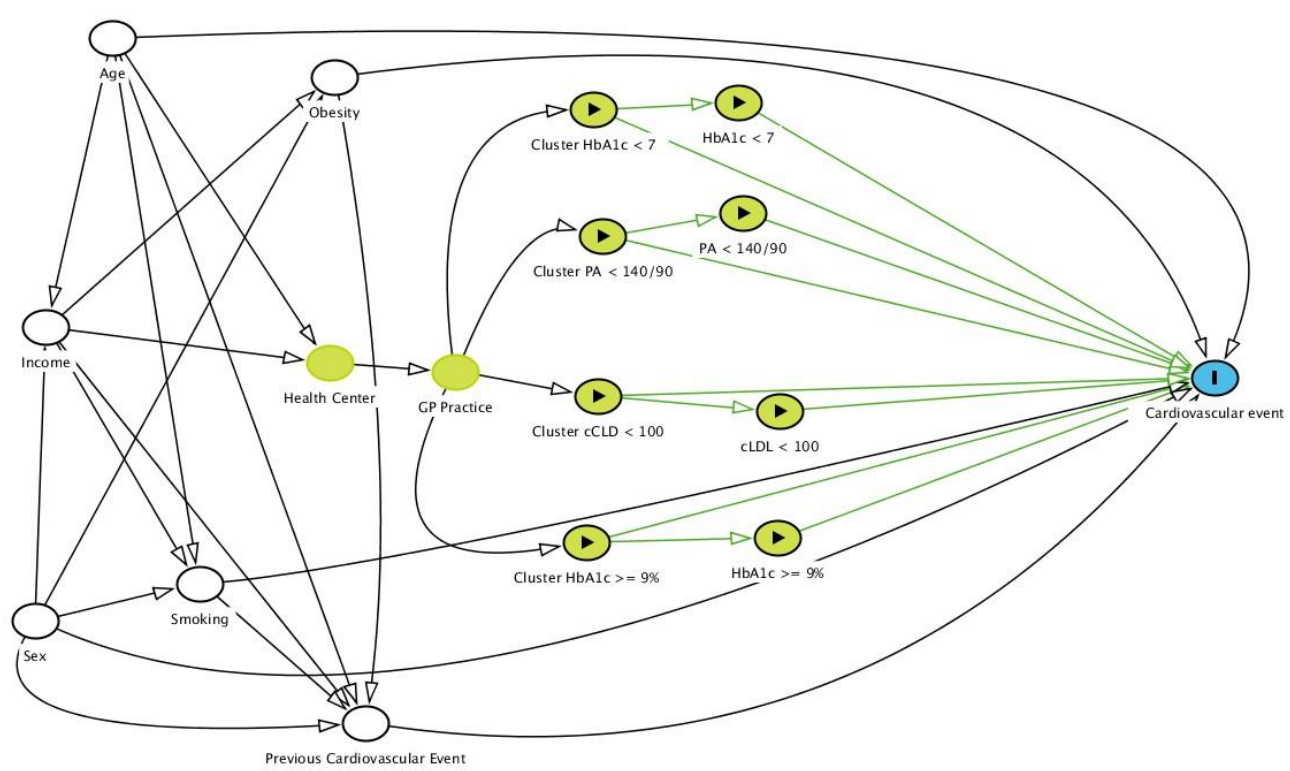

Figure 2. Adjusted Directed Acyclic Graph (DAG) of the effect of Cluster of $\mathrm{HbAc}>=9 \%$ (exposure) on Cardiovascular event (outcome). Adjusted variables (white color), ancestors of exposure (green), exposure (green \& ) Outcome (Blue \&l) Based on DAGitty version 3.0.

To calculate the probability of a patient meeting an indicator above the 5-year follow-up average, we used logistic regression calculating Odds Ratios, with 95\% confidence intervals, between patients included in the GP practices group with the highest level in each indicator versus the lowest group. We adjusted the models for age, sex, low-income status, and a previous CVE

Finally, we used Cox regression to estimate the excess risk of admission for a CVE associated with T2D control and belonging to the GP practices cluster with the highest score in the control indicators, adjusted for age, sex, low income, obesity, current smoking, and history of a CVE before admission.

\section{Results}

\subsection{Descriptive statistics}

The mean population of the dynamic cohort from 2012 to 2016 was 480637 (243129 females and 237508 males). Table S1 shows the descriptive indicators of the studied population. In 2012 the prevalence of T2D was 4.14\%, increasing to 5.05\% in 2016, being all years higher in men. The mean age of patients with T2D during 2021-2016 was 67.59 years, compared to 48.73 years in nondiabetic patients. The age-standardized prevalence of T2D in $\geq 18$ years reached in 2016 was $5.05 \%$ (women: $4.30 \%$ and men: $5.83 \%$ ). The proportion of people with low income in 2012 in nondiabetic patients was $3.68 \%$. In patients with diabetes, it was $4.57 \%$. This proportion was progressively increased in the two groups during the follow-up years to $4.01 \%$ and $5.26 \%$, respectively, in 2016. In all years, the proportion of women with low income is higher. The proportion of obese people without T2D was $25.15 \%$ in 2012 . This proportion was slightly decreasing to $23.96 \%$ in 2016 . On the contrary, the prevalence of obesity in patients with diabetes increased from 46.04 to $48.08 \%$. The 
proportion of smokers in nondiabetic patients was $24.75 \%$ in 2012 , experiencing a decrease to $23.57 \%$. The proportion of patients with TD2 smokers in 2012 was $17.01 \%$, experiencing a slight reduction at the end of the period to $16.85 \%$. The age group with the highest prevalence of T2D was $75-84$ years old (15.96\% in 2016). The highest increase in the prevalence of diabetes was in persons over 85 years of age. Diabetes prevalence has increased in this age group from $7.44 \%$ in 2012 to $14.86 \%$ in 2016 (an $89.5 \%$ increase).

The DAG shows the relations between variables. Age and socioeconomic status influence on domicile and Health center. GP practices associated with preventive measures clusters. It also shows the effects of obesity, smoking, and antecedents of CVE on the occurrence of CVE (Figure 1,2)

\subsection{Multivariate cluster analysis of GP practices}

The prevalence adjusted in multivariate analysis is $65.6 \%$ higher in males [(OR 1.658 (95\% CI: 1.610-1.702)]. People who have suffered an admission for a CVE are $27.6 \%$ more likely to have diabetes [OR: 1.276 (95\% CI: 1.211-1.344)]. Belonging to a cluster of GP practices with a higher level of detection is associated with being diagnosed with T2D 40.2\% more, compared to GP practices with a lower level of diagnosis [OR: 1.402 (95\% CI:1.363-1.411)] (Table 1).

Table 1 Variability of control indicators by GP Practices

\begin{tabular}{|c|c|c|c|c|c|}
\hline Variable & Mean & $\begin{array}{l}\text { Number of } \\
\text { highest } \\
\text { and lowest } \\
\text { scoring } \\
\text { clusters }\end{array}$ & $\begin{array}{l}\text { Mean of } \\
\text { clusters } \\
\text { with the } \\
\text { highest } \\
\text { score }\end{array}$ & $\begin{array}{l}\text { Mean of } \\
\text { clusters } \\
\text { with the } \\
\text { lowest } \\
\text { score }\end{array}$ & $\begin{array}{c}\text { Coefficient } \\
\text { Variation } \\
\text { between } \\
\text { general } \\
\text { practices }\end{array}$ \\
\hline $\begin{array}{c}\text { Standardized } \\
\text { prevalence } \\
(2016)\end{array}$ & $5.74 \dagger$ & $101 / 327$ & $8.20 \dagger$ & $4.83 \dagger$ & 42.32 \\
\hline HbA1c $<7 \%$ * & 47.34 & $360 / 72$ & 52.14 & 23.34 & 31.72 \\
\hline $\mathrm{HbA} 1 \mathrm{c}>=9 \% *$ & 15.65 & $210 / 222$ & 21.42 & 10.12 & 47.41 \\
\hline $\begin{array}{c}\mathrm{PA}<140 / 90 \\
\mathrm{mmHg}^{*}\end{array}$ & 52.52 & $243 / 188$ & 61.18 & 41.39 & 25.45 \\
\hline $\begin{array}{c}\text { LDL-C }<100 \\
\mathrm{mg} / \mathrm{dl}^{*}\end{array}$ & 46.16 & $180 / 252$ & 57.36 & 38.15 & 28.12 \\
\hline
\end{tabular}

* Average value of \% compliance by general practices over the five years. $\dagger$ Age-standardized prevalence. $(4$ General practices were eliminated due to high outlier values.)

Patients in the best control GP practices cluster are 2.5 times more likely to have HbA1c $<7 \%$ [OR: 2.457 (95\% CI: 2.291-3.636)]. Poor HbA1c control $\geq 9 \%$ is $72.9 \%$ more likely in GP practices in the worst control cluster [OR: 1.729 (95\% CI:1.631-1.834)]. BP control <140/90 $\mathrm{mmHg}$ is somewhat better in women, worsens slightly with age, low-income level, and persons who have suffered an admission for a vascular event. The probability of meeting the indicator is $83.3 \%$ higher in patients in the best control cluster GP practices [OR: 1.833 (95\% CI: 1.757-1.913)]. Control of LDL $<100 \mathrm{mg} / \mathrm{dL}$ is $40.8 \%$ higher in men [OR: 1.408 (95\% CI: 1.348-1.469)], increases slightly with age, and there are no differences according to income level. (Table 2) 
Table 2: Odds Ratios of having met the indicator above the 5-year mean.

\begin{tabular}{|c|c|c|c|c|c|}
\hline Variables & $\begin{array}{c}\text { Sex }^{* *} \\
\text { OR } \\
(95 \% \mathrm{CI})\end{array}$ & $\begin{array}{c}\text { Age } \\
\text { OR } \\
(95 \% \mathrm{CI})\end{array}$ & $\begin{array}{c}\text { Low } \\
\text { Income } \\
\text { OR } \\
(95 \% \mathrm{CI})\end{array}$ & $\begin{array}{c}\text { Hospital } \\
\text { admission } \\
\text { for CV } \\
\text { event } \\
\text { OR } \\
(95 \% \mathrm{CI})\end{array}$ & $\begin{array}{c}\text { General } \\
\text { practices } \\
\text { cluster } \dagger \\
\text { OR } \\
(95 \% \mathrm{CI})\end{array}$ \\
\hline $\begin{array}{c}\text { Standardized } \\
\text { prevalence } \\
\text { (2016) }\end{array}$ & $\begin{array}{c}1.656 \\
(1.614-1.700)\end{array}$ & $\begin{array}{c}1.056 \\
(1.055-1.057)\end{array}$ & $\begin{array}{c}2.111 \\
(1.992-2.237)\end{array}$ & $\begin{array}{c}1.276 \\
(1.211-1.344)\end{array}$ & $\begin{array}{c}1.402 \\
(1.363-1.411)\end{array}$ \\
\hline $\mathrm{HbA} 1 \mathrm{c}<7 \% *$ & $\begin{array}{c}1.099 \\
(1.053-1.148)\end{array}$ & $\begin{array}{c}1.001 \\
(0.999-1.002)\end{array}$ & $\begin{array}{c}0.801 \\
(0.721-0.890)\end{array}$ & $\begin{array}{c}0.529 \\
(0.490-0.571)\end{array}$ & $\begin{array}{c}2.457 \\
(2.291-3.636)\end{array}$ \\
\hline $\mathrm{HbA} 1 \mathrm{c} \geq 9 \% *$ & $\begin{array}{c}0.951 \\
(0.896-1.009)\end{array}$ & $\begin{array}{c}0.980 \\
(0.978-0.982)\end{array}$ & $\begin{array}{c}1.447 \\
(1.279-1.637)\end{array}$ & $\begin{array}{c}1.354 \\
(1.227-1.495)\end{array}$ & $\begin{array}{c}1.729 \\
(1.631-1.834)\end{array}$ \\
\hline $\begin{array}{c}\mathrm{PA}<140 / 90 \\
\mathrm{mmHg} *\end{array}$ & $\begin{array}{c}0.909 \\
(0.871-0.949)\end{array}$ & $\begin{array}{c}0.979 \\
(0.978-0.981)\end{array}$ & $\begin{array}{c}0.865 \\
(0.780-0.961)\end{array}$ & $\begin{array}{c}0.920 \\
(0.855-0.990)\end{array}$ & $\begin{array}{c}1.833 \\
(1.757-1.913)\end{array}$ \\
\hline $\begin{array}{c}\text { LDL-C }<100 \\
\mathrm{mg} / \mathrm{dl}{ }^{*}\end{array}$ & $\begin{array}{c}1.408 \\
(1.348-1.469)\end{array}$ & $\begin{array}{c}1.006 \\
(1.004-1.007)\end{array}$ & $\begin{array}{c}1.009 \\
(0.909-1.121)\end{array}$ & $\begin{array}{c}0.880 \\
(0.818-0.947)\end{array}$ & $\begin{array}{c}1.728 \\
(1.657-1.802)\end{array}$ \\
\hline
\end{tabular}

* Average value of $\%$ compliance by general practices over the five years ${ }^{* *}$ Male over female $\uparrow$ Adjusted for sex, age, low income

\subsection{Cox regression.}

The probability of admission for a CVE increases with age, male sex, low income, previous history of a CVE obesity, having $\mathrm{HbA} 1 \mathrm{c} \geq 9 \%$, and the patient belonging to a GP practice in the cluster of $\mathrm{HbA} 1 \mathrm{C} \geq 9 \%$ worst control. In contrast, it decreases in those patients with $\mathrm{HbA} 1 \mathrm{c}<7 \%, \mathrm{BP}<140 / 90 \mathrm{mmHg}$, and LD-C $<100 \mathrm{mg} / \mathrm{dl}$. There is no significant difference between GP practices clusters by HbA1c $<7 \%$, BP 140/90, LDL-C $<100 \mathrm{mg} / \mathrm{dl}$, or being a smoker (Table 3). 
Table 3 Cox regression model to analyze the risk of admission for a cardiovascular event in patients with type 2 Diabetes

\begin{tabular}{cccc}
\hline Variable & HR & $\mathbf{9 5 \%}$ CI & p \\
\hline Age & 1.339 & $1.189-1.507$ & $<0.001$ \\
\hline Sex $^{*}$ & 1.034 & $1.028-1.040$ & $<0.001$ \\
\hline Low Income & 1.484 & $1.129-1.950$ & 0.005 \\
\hline $\begin{array}{c}\text { History of cardiovascular } \\
\text { event prior to admission }\end{array}$ & 17.885 & $15.499-20.638$ & $<0.001$ \\
\hline HbA1c $<7 \%{ }^{* *}$ & & \\
\hline HbA1c $>=9 \% *$ & 0.670 & $0.579-0.775$ & $<0.001$ \\
\hline BP $<140 / 90 \mathrm{mmHg}{ }^{* *}$ & 1.665 & $1.339-2.070$ & $<0.001$ \\
\hline LDL-C $<100 \mathrm{mg} / \mathrm{dl}^{* *}$ & 0.794 & $0.682-0.924$ & 0.003 \\
\hline Cluster indicator $\mathrm{HbA} 1 \mathrm{c}<7 \%$ & 0.844 & $0.737-0.967$ & 0.015 \\
\hline Cluster indicator HbA1c $>=9 \%$ & 1.091 & $0.927-1.283$ & 0.293 \\
\hline Cluster indicator PA $<140 / 90 \mathrm{mmHg}$ & 1.147 & $1.030-1.277$ & 0.012 \\
\hline Cluster indicator LDL-C $<100 \mathrm{mg} / \mathrm{dl}$ & 1.082 & $0.968-1.210$ & 0.166 \\
\hline Current smoker & 0.919 & $0.824-1.026$ & 0.132 \\
\hline Obesity $(\mathrm{BMI}>30)$ & 1.043 & $0.935-1.164$ & 0.451 \\
\hline
\end{tabular}

* Male over female ** Average 5-year compliance

\section{Discussion}

\subsection{Strengths and limitations}

Our study had several strengths. First, we study the entire population of Navarra, an area in the north of Spain with more than 600.000 inhabitants. This fact minimizes the selection risk of bias. We have used cluster analysis to classify GP practices on compliance with the indicators rather than other methods. It identifies clusters in which intragroup variability is minimal and maximizes extra group variability. Thus, the individuals in each cluster are very similar and different from the other clusters. This analysis allows us to correct the drawbacks of more straightforward methods such as deciles or quartiles, and others that include individuals with outliers may bias.

Our population is so large that slight differences, without clinical relevance, can be significant. Therefore, using the Hazard Ratio or Odds Ratio to measure the association's strength allows us to visualize better the most clinically relevant differences between the different GP practices in compliance with the quality indicators.

In this study, we do not know how many years the general practitioner was in a GP practice, so it would be interesting to analyze the continuity of the same physician in each GP practice in other studies.

Our study has been carried out based on the electronic records of health professionals during patient care, being a faithful reflection of clinical practice. This is one of the strengths of this type of study. But they may have biases due to limitations in the quality of the records. Studies with large administrative databases often show high accuracy in the diagnostic and treatment aspects. Still, they are subject to misclassification problems related to underreporting of lifestyle that affect the outcome of interest. In contrast, in many traditional "ad hoc" epidemiological studies, there is a great deal of information on risk factors, but the clinical data is incomplete or of lower quality.

Administrative databases may be insufficient to obtain reliable estimates of the effects of preventive actions due to unmeasured confounding factors [32,33]. This can occur in both longitudinal and cross-sectional studies [34]. There may be an underreporting of 
our study's lifestyle or clinical examination data, such as smoking, BP, and weight measurements. Compared with the literature, the percentage of smokers in T2D and obese patients is similar to previous studies in Spain [18,35-38]. Laboratory data are collected automatically, so they accurately reflect what has been requested from each patient. The registry of Navarra was rated as the highest quality among the 17 Regional Health Services in Spain in patients with T2D [39]. In Navarra, studies have shown the usefulness of electronic records for assessing the quality of care of patients with T2D [7,27-29]. This study could only access data on hospital admissions for cardiovascular CVE but not mortality data. Future studies would be of great interest to analyze the risk of cardiovascular mortality in patients with T2D. [35]

\subsection{Prevalence of diabetes}

The prevalence of T2D increased over the years studied from $4.14 \%$ to $5.05 \%$. It was higher in men in all years. The mean standardized prevalence achieved in 2016 in the highest and lowest diagnosed GP practices clusters was $8.20 \%$ and $4.83 \%$, respectively. Several studies with different methodologies have analyzed the prevalence and degree of control of patients with T2D in Spain $[40,41]$. One of the main findings in the literature is that most of the studies conducted in Spain do not provide prevalence figures [20,41-44]. An exception is the epidemiological study Di@bet.es, with data from a population-based sample of 5,072 participants aged $\geq 18$ years and identified a prevalence of T2D of $13.8 \%$. (CI 95\% 12.8- 14.7), being unknown by patients in 6.0\% (CI 95\% 5.4-6.7) [36]. In our investigation, the prevalence detected is lower in both the highest and lowest detection clusters with patient visit data. In Catalonia (Spain), a study with electronic records of patient visits on a population of 3,755,038 inhabitants between 31 and 90 years of age found a prevalence of $7.6 \%$ of patients with diabetes. Although this figure is higher than our GP practices average is like the cluster with higher detection.

According to the 2014 European Health Survey, the prevalence of self-reported T2D is $6.82 \%(7.25 \%$ in men and $6.4 \%$ in women), higher than detected in our study but lower than detected by the highest detection cluster [45]. The European health survey in Spain 2017 points out that the prevalence of T2D had doubled from 1993 (4.1\%) to 2017 (7.8\%) [46]. Results from the 2017-2018 age-adjusted NAHNES survey conducted in the US among US adults 18 years and older showed a prevalence of $7.5 \%$ among non-Hispanic whites[47]. Our standardized prevalence for the population of Navarra is $5.74 \%(8.2 \%$ higher cluster and 4.83 lower cluster).

\subsection{Risk factors for cardiovascular disease}

There is a relationship between the duration of the evolution of T2D and the deterioration of lipid control [43]. In Navarra, a cross-sectional study showed that women were less likely than men to achieve HbA1c (59 vs. 61\%), LDL (35 vs. 45\%), and HDL (58 vs. $78 \%$ ) control targets and that patients under 65 years of age had worse control than older age groups. [27] Data from our study agree with these results given that men had an OR of 1.099 for $\mathrm{HbA} 1 \mathrm{c}<7 \%$ and 1.408 for LDL-C $<100 \mathrm{mg} / \mathrm{dl}$, however, BP control was better in women (OR 0.909). Another multicenter cross-sectional study found that patients with T2D had a high prevalence of cardiovascular risk factors in Spain. Control of glycemia, smoking, BP, and LDL-C was not optimal [44]. Our study observed that, on average, less than half of the patients with $\mathrm{T} 2 \mathrm{D}$ had $\mathrm{HbA} 1 \mathrm{c}<7 \%$ or LDL-C $<100 \mathrm{mg} / \mathrm{dl}$ in the five years of follow-up. As for BP, the percentage of control is somewhat higher, $52 \%$. In a cohort study conducted in primary care in the Community of Madrid, cardiovascular complications were: $6.2 \%$ coronary heart disease, $3.2 \%$ peripheral vascular disease, and $2.8 \%$ stroke. In addition, it detected retinopathy in $5.9 \%$ of patients [42].

\subsection{Variability in control indicators}


We used only four quality indicators of T2D control, which different guidelines have proposed. The indicators were percentage of people with T2D per GP practice with HbA1c $<7$; percentage of people with T2D per GP practice with $\mathrm{HbA1c} \geq 9$, percentage of people with T2D per GP practice with LDL-C $<100 \mathrm{mg} / \mathrm{dl}$, and percentage of patients per GP practice with $\mathrm{BP}<140 / 90 \mathrm{mmHg}[1,4]$.

$\mathrm{HbA} 1 \mathrm{c}$ is a marker of average blood glucose concentration that is linearly related to the risk of vascular complications. $\mathrm{HbA1c}$ is very useful for the diagnosis of diabetes. Its value is increasingly discussed for treatment because the average glucose and blood glucose range is becoming critical [48]. Although $\mathrm{HbA1c}$ level is continuously associated with cardiovascular risk, different guidelines have recommended an $\mathrm{HbA} 1 \mathrm{c}<7 \%$ as the cut-off point for establishing recommendations for managing T2D [1,4]. Analysis of electronic $\mathrm{HbA} 1 \mathrm{c}$ records helps predict increased emergency department visits and hospital admissions [49]. Being in the cluster of GP practices with the best control multiplies by 2.5, the probability of having $\mathrm{HbA} 1 \mathrm{c}$ controlled. Being in a GP practice in the worst control cluster increases the likelihood of having $\mathrm{HbA} 1 \mathrm{c} \geq 9 \%$ by $73 \%$. This is a cause for concern due to the inequity involved. The American Diabetes Association (ADA) has revised its overall BP targets for patients with T2D, placing it at $<140 / 90 \mathrm{mmHg}$ [50,51]. In our study, the probability of control in the best control cluster is almost double. According to the recommendations of the clinical guidelines, we have taken LDL-C $<100 \mathrm{mg} / \mathrm{dl}$ as a reference for lipid control [2,4]. Again, we detected significant differences between the clusters, with almost double the probability of having controlled LDL-C in the best-controlled cluster.

\subsection{Variability. The risk of admission for a CVE}

The most frequent complication leading to hospitalization of T2D is stroke $(34.7 \%)$, followed by ischemic heart disease (28.7\%) [3]. Our study provides information on the risk of admission for [35] stroke and ischemic heart disease in patients with T2D. However, it has the limitation that it does not include deaths due to these causes. Still, it allows adjusting the risk of admission by age, sex, and low income, including the variability of the physician providing the care. Our study found that the risk of cardiovascular admission increases by $3.4 \%$ with each year of age. Other studies report a similar annual risk of fatal and nonfatal CVE between 2-5\% [52,53]. The risk of admission was lower in those patients with $\mathrm{HbA} 1 \mathrm{c}<7 \%$ (HR: 0.67) and increased if $\mathrm{HbA} 1$ had elevated values $>=9 \%$ (HR: 1.665 ). Our results coincide with other studies indicating an increased CVE risk with elevated HbA1c levels [54-56].

Similarly, lipid and BP control were protective factors. There was no difference in admissions between patients whose GP was in the higher control cluster of $\mathrm{HbA} 1 \mathrm{c}<7 \%$ and those in the lower cluster. The same happened with BP $<140 / 90 \mathrm{mmHg}$ and LDL-C $<100 \mathrm{mg} / \mathrm{dl}$ clusters. Differences were found between clusters with a higher proportion of patients with poor control of $\mathrm{HbA1c} \geq 9 \%$. A GP practice located in a poorly controlled cluster entails an additional risk of admission for a CVE of $14.7 \%$, and this risk is independent of the risk that the patients may have when their $\mathrm{HbA} 1 \mathrm{c} \geq 9 \%$ is uncontrolled.

\subsection{Implications for research and practice}

Variability in clinical practice is a factor that influences the health of the population. It has been studied how professionals' knowledge and interest in specific pathologies influence the control of different health indicators [21,22,24]. On the other hand, another factor that influences care is continuity of care. Previous studies have shown that having a primary care physician that knows their patients for many years is a protective factor in admissions and mortality [57,58]. We have not evaluated this item because it does not appear in the database analyzed.

With a small number of indicators, our study provides information on the technical quality achieved in clinical practice in the care of patients with T2D, identifying variability 
among primary care providers. Cluster analysis allows us to obtain homogeneous groups of GP practices by identifying those who achieve better or worse results in routine clinical practice. Odds ratios quantify the differences between clusters, showing compliance with the indicators between the different GP practices. We detected a significant equity problem according to the health care providers and socio-economic level.

The methodology used would be helpful to establish incentives through benchmarking strategies that introduce a comparative evaluation with the best and most efficient practices. This type of strategy is a method of continuous improvement in various business sectors, including the health sector [59-61]

Supplementary Materials: The following is available online at http://www.mdpi.com/ Table S1: Descriptive indicators of the population of Navarra, cohort 2012 to 2016 (>=18 years) stratified by sex.

Funding: Menarini supported this study with an unconditional sponsored research grant.

Author Contributions: Conceptualization, SGA, ABL, LF; methodology, SGA, ABL; data curation ABL, LF; writing - original draft preparation, SGA, ABL; writing - review and editing, SGA, IAO, ABL, LF, FGG. LGA; visualization, FGG, IAO, LGA; supervision, ABL, LF; funding acquisition, LF. All authors have read and agreed to the published version of the manuscript.

Institutional Review Board Statement: The APNA study received approvals from the Spanish Agency for Medicines and Health Products of the Ministry of Health, Social Services, and Equality under code ABL-MET-2013-01 on 9 December 2013 and from the Clinical Research Ethics Committee of the Government of Navarra. (CEIC) number 3/2014 on 26 March 2014 and number 83/2014 on 30 September 2014.

Informed Consent Statement: The database is an administrative database of Navarra Health Service. Clinical Records were collected routinely during attendance in primary health care and hospitals. All users of Navarra Health Services know that their clinical records are registered, and that can be used for epidemiological research. According to Data Protection Law, they have the right to the cancellation of their records.

Data Availability Statement: The datasets generated for this study are unavailable due to the data protection law.

Conflicts of Interest: The authors declare no conflict of interest. The funders had no role neither in study design nor in the collection, analyses, interpretation of data, manuscript writing, or in the decision to publish the results".

\section{References}

1. Rakshana A, Rawshani A, Franzén S, et al. Risk Factors, Mortality, and Cardiovascular Outcomes in Patients with Type 2 Diabetes. N Engl J Med 2018;379:633-44. doi:10.1056/NEJMoa1800256

2. Cho NH, Shaw JE, Karuranga S, et al. IDF Diabetes Atlas: Global estimates of diabetes prevalence for 2017 and projections for 2045. Diabetes Res Clin Pract 2018;138:271-81. doi:10.1016/j.diabres.2018.02.023

3. Cheng S-W, Wang C-Y, Ko Y. Costs and Length of Stay of Hospitalizations due to Diabetes-Related Complications. J Diabetes Res 2019;2019:1-6. doi:10.1155/2019/2363292

4. American Diabetes Association. Cardiovascular disease and risk management: Standards of medical care in diabetes 2021. Diabetes Care 2021;44:S125-50. doi:10.2337/dc21-S010

5. The Emerging Risk Factors Collaboration. Diabetes mellitus, fasting blood glucose concentration, and risk of vascular disease: a collaborative meta-analysis of 102 prospective studies. Lancet 2010;375:2215-22. doi:10.1016/S0140-6736(10)60484-9

6. Sattar N, Rawshani A, Franzén S, et al. Age at Diagnosis of Type 2 Diabetes Mellitus and Associations With Cardiovascular and Mortality Risks. Circulation 2019;139:2228-37. doi:10.1161/CIRCULATIONAHA.118.037885

7. Ibáñez B, Galbete A, Goñi MJ, et al. Socioeconomic inequalities in cardiometabolic control in patients with type 2 diabetes. BMC Public Health 2018;18:408. doi:10.1186/s12889-018-5269-0

8. Walker J, Halbesma N, Lone N, et al. Socioeconomic status, comorbidity and mortality in patients with type 2 diabetes mellitus in Scotland 2004-2011: a cohort study. J Epidemiol Community Health 2016;70:596-601. doi:10.1136/jech-2015-206702

9. Saydah SH, Imperatore G, Beckles GL. Socioeconomic Status and Mortality: Contribution of health care access and psychological distress among U.S. adults with diagnosed diabetes. Diabetes Care 2013;36:49-55. doi:10.2337/dc11-1864 
10. Saydah S, Lochner K. Socioeconomic Status and Risk of Diabetes-Related Mortality in the U.S. Public Health Rep 2010;125:37788. doi:10.1177/003335491012500306

11. Dalsgaard E-M, Vestergaard M, Skriver MV, et al. Socioeconomic position and cardiovascular risk factors among people with screen-detected Type 2 DM: Six-year follow-up of the ADDITION-Denmark trial. Prim Care Diabetes 2014;8:322-9. doi:10.1016/j.pcd.2014.01.006

12. Dalsgaard E-M, Skriver M V., Sandbaek A, et al. Socioeconomic Position, Type 2 Diabetes and Long-Term Risk of Death. PLoS One 2015;10:e0124829. doi:10.1371/journal.pone.0124829

13. O'Kane MJ, McMenamin M, Bunting BP, et al. The relationship between socioeconomic deprivation and metabolic/cardiovascular risk factors in a cohort of patients with type 2 diabetes mellitus. Prim Care Diabetes 2010;4:241-9. doi:10.1016/j.pcd.2010.08.004

14. Gerstein HC, Islam S, Anand S, et al. Dysglycaemia and the risk of acute myocardial infarction in multiple ethnic groups: an analysis of 15,780 patients from the INTERHEART study. Diabetologia 2010;53:2509-17. doi:10.1007/s00125-010-1871-0

15. Lehto S, Ronnemaa T, Haffher SM, et al. Dyslipidemia and Hyperglycemia Predict Coronary Heart Disease Events in MiddleAged Patients With NIDDM. Diabetes 1997;46:1354-9. doi:10.2337/diab.46.8.1354

16. Hoerger TJ, Segel JE, Gregg EW, et al. Is Glycemic Control Improving in U.S. Adults? Diabetes Care 2008;31:81-6. doi:10.2337/dc07-1572

17. Stark Casagrande S, Fradkin JE, Saydah SH, et al. The Prevalence of Meeting A1C, Blood Pressure, and LDL Goals Among People With Diabetes, 1988-2010. Diabetes Care 2013;36:2271-9. doi:10.2337/dc12-2258

18. DHHS. National Diabetes Statistics Report, 2020. Natl Diabetes Stat Rep 2020: 2.

19. Assmann G, Schulte H. The Prospective Cardiovascular Münster (PROCAM) study: Prevalence of hyperlipidemia in persons with hypertension and/or diabetes mellitus and the relationship to coronary heart disease. Am Heart J 1988;116:1713-24. doi:10.1016/0002-8703(88)90220-7

20. Mata Cases M, Artola Menéndez S, Díez Espino J, et al. Actualización de 2020 del algoritmo de tratamiento de la hiperglucemia en la diabetes mellitus tipo 2 de la redGDPS. Diabetes Práctica 2020;11:41-76. doi:10.26322/2013.7923.1505400531.03

21. Casanova L, Bocquier A, Cortaredona S, et al. Membership in a diabetes-care network and adherence to clinical practice guidelines for treating type 2 diabetes among general practitioners: A four-year follow-up. Prim Care Diabetes 2016;10:342-51. doi:10.1016/j.pcd.2016.07.001

22. Khunti K, Ganguli S, Baker R, et al. Features of primary care associated with variations in process and outcome of care of people with diabetes. 2001.

23. Nøkleby K, Berg TJ, Mdala I, et al. Variation between general practitioners in type 2 diabetes processes of care. Prim Care Diabetes Published Online First: January 2021. doi:10.1016/j.pcd.2020.11.018

24. Tran AT, Bakke Å, Berg TJ, et al. Are general practitioners characteristics associated with the quality of type 2 diabetes care in general practice? Results from the Norwegian ROSA4 study from 2014. Scand J Prim Health Care 2018;36:170-9. doi:10.1080/02813432.2018.1459238

25. Franch Nadal J, Artola Menéndez S, Diez Espino J, et al. [The evolution of quality care indicators of patients with type 2 diabetes in the Spanish primary care (1996-2007). The RedGEDAPS quality of care program]. Med Clin (Barc) 2010;135:600-7. doi:10.1016/j.medcli.2009.06.033

26. Mata-Cases M, Roura-Olmeda P, Berengué-Iglesias M, et al. Fifteen years of continuous improvement of quality care of type 2 diabetes mellitus in primary care in Catalonia, Spain. Int J Clin Pract 2012;66:289-98. doi:10.1111/j.1742-1241.2011.02872.x

27. Cambra K, Galbete A, Forga L, et al. Sex and age differences in the achievement of control targets in patients with type 2 diabetes: results from a population-based study in a South European region. BMC Fam Pract 2016;17:144. doi:10.1186/s12875-016-0533-9

28. Galbete A, Cambra K, Forga L, et al. Achievement of cardiovascular risk factor targets according to sex and previous history of cardiovascular disease in type 2 diabetes: A population-based study. J Diabetes Complications 2019;33:107445. doi:10.1016/j.jdiacomp.2019.107445

29. Brugos-Larumbe A, Aldaz-Herce P, Guillen-Grima F, et al. Assessing variability in compliance with recommendations given by the International Diabetes Federation (IDF) for patients with type 2 diabetes in primary care using electronic records. The APNA study. Prim Care Diabetes 2018;12:34-44. doi:10.1016/j.pcd.2017.06.008

30. Martin-Rodriguez E, Guillen-Grima F, Martí A, et al. Comorbidity associated with obesity in a large population: The APNA study. Obes. Res. Clin. Pract. 2015;9:435-47. doi:10.1016/j.orcp.2015.04.003

31. Textor J, van der Zander B, Gilthorpe MS, et al. Robust causal inference using directed acyclic graphs: the R package 'dagitty.' Int J Epidemiol 2017;:dyw341. doi:10.1093/ije/dyw341

32. García-Albéniz X, Hsu J, Bretthauer M, et al. Estimating the Effect of Preventive Services With Databases of Administrative Claims: Reasons to Be Concerned. Am J Epidemiol 2019;188:1764-7. doi:10.1093/aje/kwz049

33. García-Albéniz X, Hsu J, Bretthauer M, et al. Response to Commentary Estimating the Effect of Preventive Services With Databases of Administrative Claims: Reasons to Be Concerned. ;188. doi:10.1093/aje/kwz049

34. MacDonald SC, Hernán MA, McElrath TF, et al. Assessment of recording bias in pregnancy studies using health care databases: An application to neurologic conditions. Paediatr Perinat Epidemiol 2018;32:281-6. doi:10.1111/ppe.12459

35. Vinagre I, Mata-Cases M, Hermosilla E, et al. Control of glycemia and cardiovascular risk factors in patients with type 2 diabetes in primary care in Catalonia (Spain). Diabetes Care 2012;35:774-9. doi:10.2337/dc11-1679

36. Soriguer F, Goday A, Bosch-Comas A, et al. Prevalence of diabetes mellitus and impaired glucose regulation in Spain: The Di@bet.es Study. Diabetologia 2012;55:88-93. doi:10.1007/s00125-011-2336-9 
37. Mata-Cases M, Franch-Nadal J, Real J, et al. Glycaemic control and antidiabetic treatment trends in primary care centres in patients with type 2 diabetes mellitus during 2007-2013 in Catalonia: a population-based study. BMJ Open 2016;6:e012463. doi:10.1136/bmjopen-2016-012463

38. Larrañaga I, Arteagoitia JM, Rodriguez JL, et al. Socio-economic inequalities in the prevalence of Type 2 diabetes, cardiovascular risk factors and chronic diabetic complications in the Basque Country, Spain. Diabet Med 2005;22:1047-53. doi:10.1111/j.14645491.2005.01598.x

39. Navarro-Pérez J, Franch-Nadal J, Artola-Menéndez S, et al. La historia clínica electrónica y los registros sobre diabetes en España. Av diabetol 2011;:128-36.

40. Herrero A, Garzón G, Gil A, et al. [Control of cardiovascular risk factors among patients with diabetes with and without cardiovascular disease]. Semergen 2015;41:354-61. doi:10.1016/j.semerg.2014.07.005

41. Arroyo J, Badía X, de la Calle H, et al. Tratamiento de los pacientes con diabetes mellitus tipo 2 en atención primaria en España. Med Clin (Barc) 2005;125:166-72. doi:10.1157/13077139

42. Arrieta F, Piñera M, Iglesias P, et al. Metabolic control and chronic complications during a 3-year follow-up period in a cohort of type 2 diabetic patients attended in primary care in the Community of Madrid (Spain). Endocrinol Nutr 2014;61:11-7. doi:10.1016/j.endonu.2013.09.002

43. Benito López P, García Mayor R, Puig Domingo M, et al. [Pathological characteristics of patients with diabetes mellitus type 2, in Spanish Primary Care]. Rev Clin Esp 2004;204:18-24. doi:10.1157/13056787

44. Orozco-Beltrán D, Gil-Guillen VF, Quirce F, et al. Control of diabetes and cardiovascular risk factors in patients with type 2 diabetes in primary care. The gap between guidelines and reality in Spain. Int J Clin Pract 2007;61:909-15. doi:10.1111/j.17421241.2007.01367.x

45. Ministerio de Sanidad Servicios Sociales e Igualdad de España. Informe Encuesta Europea de Salud 2014. Madrid: 2014.

46. Ministerio de Sanidad C y BS. Nota Técnica Encuesta Nacional de Salud. España 2017 Principales resultados. Madrid: 2018.

47. CDC. Informe nacional de estadísticas de la diabetes. Atlanta GA: 2017.

48. Selvin E, Steffes MW, Zhu H, et al. Glycated Hemoglobin, Diabetes, and Cardiovascular Risk in Nondiabetic Adults. N Engl J Med 2010;362:800-11. doi:10.1056/NEJMoa0908359

49. Birtwhistle R, Green ME, Frymire E, et al. Hospital admission rates and emergency department use in relation to glycated hemoglobin in people with diabetes mellitus: a linkage study using electronic medical record and administrative data in Ontario. C Open 2017;5:E557-64. doi:10.9778/cmajo.20170017

50. Rizvi AA. Addressing hypertension in the patient with type 2 diabetes mellitus: pathogenesis, goals, and therapeutic approach Eur Med journal Diabetes 2017;5:84-92.http://www.ncbi.nlm.nih.gov/pubmed/29129996

51. Cardiovascular Disease and Risk Management. Diabetes Care 2017;40:S75-87. doi:10.2337/dc17-S012

52. Morrish NJ, Stevens LK, Fuller JH, et al. Incidence of macrovascular disease in diabetes mellitus: the London cohort of the WHO Multinational Study of Vascular Disease in Diabetics. Diabetologia 1991;34:584-9. doi:10.1007/BF00400278

53. Stamler J, Vaccaro O, Neaton JD, et al. Diabetes, Other Risk Factors, and 12-Yr Cardiovascular Mortality for Men Screened in the Multiple Risk Factor Intervention Trial. Diabetes Care 1993;16:434-44. doi:10.2337/diacare.16.2.434

54. Cavero-Redondo I, Peleteiro B, Álvarez-Bueno C, et al. Glycated haemoglobin A1c as a risk factor of cardiovascular outcomes and all-cause mortality in diabetic and non-diabetic populations: a systematic review and meta-analysis. BMJ Open 2017;7:e015949. doi:10.1136/bmjopen-2017-015949

55. Khaw K-T, Wareham N, Bingham S, et al. Association of Hemoglobin A 1c with Cardiovascular Disease and Mortality in Adults: The European Prospective Investigation into Cancer in Norfolk. Ann Intern Med 2004;141:413. doi:10.7326/0003-4819-141-6200409210-00006

56. Eeg-Olofsson K, Cederholm J, Nilsson PM, et al. New aspects of HbA1c as a risk factor for cardiovascular diseases in type 2 diabetes: an observational study from the Swedish National Diabetes Register (NDR). J Intern Med 2010;268:471-82. doi:10.1111/j.1365-2796.2010.02265.x

57. Leleu H, Minvielle E. Relationship between longitudinal continuity of primary care and likelihood of death: analysis of national insurance data. PLoS One 2013;8:e71669. doi:10.1371/journal.pone.0071669

58. Hoertel N, Limosin F, Leleu H. Poor longitudinal continuity of care is associated with an increased mortality rate among patients with mental disorders: results from the French National Health Insurance Reimbursement Database. Eur Psychiatry 2014;29:358-64. doi:10.1016/j.eurpsy.2013.12.001

59. Ettorchi-Tardy A, Levif M, Michel P. Benchmarking: a method for continuous quality improvement in health. Healthc Policy 2012;7:e101-19.http://www.ncbi.nlm.nih.gov/pubmed/23634166

60. Hermans MP, Elisaf M, Michel G, et al. Benchmarking is associated with improved quality of care in type 2 diabetes: the OPTIMISE randomized, controlled trial. Diabetes Care 2013;36:3388-95. doi:10.2337/dc12-1853

61. Lee AS, Colagiuri S, Flack JR. Successful implementation of diabetes audits in Australia: the Australian National Diabetes Information Audit and Benchmarking (ANDIAB) initiative. Diabet Med 2018;35:929-36. doi:10.1111/dme.13635 